\title{
Studying a Foreign Language in Creative Higher Education Institutions: the Problem of Forming Motivation
}

\author{
Maria Bets \\ Department of Theatre History, Literature and Music \\ Novosibirsk State Theatre Institute \\ Novosibirsk, Russia \\ vollens@mail.ru
}

\author{
Oksana Rtischeva \\ Department of Foreign Languages \\ Kemerovo State Institute of Culture \\ Kemerovo, Russia \\ ortishheva@mail.ru
}

\begin{abstract}
Organizing educational process requires considering professional interests of students. The creative orientation of higher education institutions dictates special approach for creating favorable conditions for learning the material. Realizing the needs of the students, accounting their interest at material selection, the tolerant attitude towards the identity of everyone these are the basis of motivated training. During this process the foreign language skills are formed. The article considers the possibilities of creating external motivation of the students within the discipline "Foreign language". Expansion of communication borders out of limits of the habitual and familiar language environment is an integral part of the modern world in which the processes of globalization and linguistic unification force to master additional foreign languages. Attracting attention of the students to this problem is one of the fundamental motivating principles.
\end{abstract}

Keywords-motivation; motive; motivated education; external and internal education

\section{INTRODUCTION}

One of the main aspects of successful training is a motivation of students, which has a positive impact not only on a process of training, but also on its result. Motivated training at higher education institution is a fundamental basis, because students gain skills for independent work and selforganization; and training process becomes conscious for them. Such type of work defines the purposes and tasks from the students, and it has a system character. However, such views on education is ideal, as the students can spend potential opportunities for the distracting processes and lose motivational thread which connects them with the training process due to their psychological and social immaturity. Thus, the student needs help of the teacher conducting a certain discipline and whose activity is connected not only with transferring knowledge, but also with creating favorable motivational conditions for training process at which there would be "a mastering richness of world and national traditions, past values in their communications with the present, formation of a complete picture of the world and historical consciousness" [1].

\section{MOTIVATION CONCEPT}

Firstly, it is proposed to consider the "motivation" concept, its types and its connection with specific and personal features of the student. Bogdanov Yu.V. considers motivation as "a motivation process of the student to educational activity under the influence of internal and external driving forces" [2].

Modern scientists consider two theories of motivation: substantial and procedural. "Substantial theories of motivation analyze the content of such categories as requirements and remunerations and also their impact on behavior of performers. In procedural theories the behaviors of people taking into account both requirements and remunerations, and other factors" [2].

The motivation basis category is the motive. The motive has complex structure, which depends on specific and personal features of the student. The motive includes emotions, interests, requirements, ideals and installations. "Therefore the motives are complex dynamic systems in which the choice and decision-making, the analysis and assessment of the choice are carried out" [3]. At the same time, motives in the course of training can be changed; gain new characteristics or can be extinguished at all. Each student independently defines motives influencing the subsequent scenario for developing the process of training.

\section{TYPES OF MOTIVES}

Modern scientists suggest the following classification of the motives according to the orientation and contents:

- social motives are connected with desire to reach a certain position in a society; to get a social status, according to personal requirements;

- cognitive motives are connected with the aspiration to obtain new knowledge and high-quality experience in training process; 
- professional and valuable motives are connected with realizing necessity of the gained knowledge for further professional activity;

- esthetic motives are connected with receiving pleasure from training process, using it to get different opportunities;

- communicative motives are connected with getting new acquaintances having similar interest in education process;

- status and position motives are connected with the aspiration to be approved in society due to training process; to gain recognition of the educational or public work;

- traditional and historical motives are connected with traditional public stereotypes on necessity to get education;

- utilitarian and practical motives are aiming to get knowledge in one subject; ignoring additional information; unwillingness to be engaged in all-round development;

- educational and informative motives are guided to getting new knowledge;

- unconscious motives are connected with formal receiving education under the influence of external factors; lack of desire to get new knowledge; inert relation to studying and getting knowledge; misunderstanding for their further application.

Besides, motives can be divided into external and internal. External motives function as a product of life of the personality in society. They are dictated by modern conditions and realities of society, opinion and desire of the third parties. They create borders within which the personality has to act, without entering the conflict with people around. Rejecting such conditions, neglecting external motives can lead to confrontation and decrease in level of motivation or generation of motivation for other type of activity.

Internal motives are traditionally perceived as the most effective. They mean activity implementation process. Each internal motive has conscious or unconscious character, but it is by all means connected with desire of the personality. Motivation emergence and further activity is a product of internal motives.

Depending on a type of motivation (external or internal) the process of education is divided into external process teaching (an active participant is the teacher, the parent or other third party) and internal - training (in this case the student gaining knowledge acts as an active participant).

It should be noted that at the correct organization of training process the external motivation could pass into internal. Thus, it is a pedagogically successful work for the teacher, and for the students educational process becomes fascinating and interesting.

\section{The Ways of CREATING EXTERnal Motivation IN CREATIVE HIGHER EDUCATION}

Furthermore, it is suggested to consider the ways for creating external motivation, internal motives of the students stimulating their further educational activity become its result. Organization of training process of the students is considered on the example of the lesson "Foreign language" at Novosibirsk State Theatrical Institute.

First of all the teacher should consider the creative atmosphere of higher education institution which defines methodical work with the students when choosing the motivating actions.

The existing state educational standard is aimed at allround development of the student. After graduation higher education institution the student has to have knowledge not only within profile discipline, but also within general education disciplines, their studying assumes transferring the minimum quantity of information, but opening the key statements of the studied subject. According to the standard the foreign language belongs to general education disciplines. Its choice is defined by the students depending on opportunities of higher education institution (pedagogical staffing, educational and methodical books, educational and working programs and etc.). One of the most popular foreign languages at higher education institution is English that is caused by its prevalence and perception as language of world communication, media and Internet. English is the language, most available to study.

Within cultural development the modern person should speak one or several foreign languages as "language is the powerful public tool forming a human stream into the ethnos, forming the nation through storage and transfer of culture, traditions and public consciousness of this speech collective" [4]. This thesis is the cornerstone of the pedagogical actions motivating students. The explanation of importance to improve foreign language skills, at least, at the level of spoken language creates a situation of personal interest in studying the discipline. The mentioned importance is connected with future profession of students (in this case a profession of the actor or director). Advantage of creative higher education institution before the others is that the students coming to it independently make the decision where to study; they consciously make their choice and set the aim to work in that sphere.

Rational and at the same time creative approach to training process means flexibility and responsiveness from the students on actions of the teacher. So the teacher should organize training process unconventionally. The students positively perceive the foreign language classes organized in a creative form. Avoiding traditional methods of teaching stimulates interest and gives positive results; there is a bilateral involvement into process. The teacher improves professional skills and develops pedagogical abilities. The students study material effectively with high results.

Another way for creating motivation is the choice of educational and methodical material. It has to meet requirements and interests of the students. "If the content of 
a training material does not demand some special work from the students on its realizing, then such training material will not satisfy, in particular, their need for continuous development of mental functions (memory, thinking, imagination), it will not develop bright emotions (positive and negative) and, therefore, will not satisfy the need for emotional saturation, and will not contribute the emergence and the development of new requirements" [5]. Besides required literature it is necessary to use additional material with relevant information. Joint conversations with the students, revealing their requirements can help the teacher to solve the problem. If the teacher finds it difficult to obtain such information from the students that often arise with the first year students when they still are under the influence of school lessons where the role of the teacher is represented to more authoritative, than it is implemented in creative higher education institution, then he can reserve option, but taking into account the general trend of an educational process.

"Learning a foreign language the cross-cultural competence is formed, generally in artificially created problem cross-cultural situation" [6], therefore, the students are interested in the themes based on comparison of two cultures of native and learned languages. Comparison can concern both the professional sphere, and household which is an integral part of life of each of the students. Insufficient life experience or lack of information on the discussed issue have to stimulate students for searching new knowledge, the teacher directs and adjusts this process taking into account the purposes of training, the principles of such training are forming communicative skills for further foreign communication. To put the students in the "hostile" language environment without speaking native language excepting cases of an explanation of the difficult questions demanding detailed study and judgment is a very effective method of training. Such method of training is a challenge for many students who got used to read and translate; and it demands from them the bigger number of efforts. Due to the above mentioned facts the idea to start learning a foreign language in a new way is very interesting. Loss of interest in studying a foreign language is connected with using earlier acquired knowledge: repeating the themes taken from the school program. Not the positive result, but the negative effect expressed in loss of the available knowledge can turn out to be consequence of it. If the student begins to master a modern foreign language, then it demands continuous efforts, hard work that gradually moves to a level of internal motivation which promotes more careful study of the material and its judgment.

The teacher needs to remember that educational process is bilateral and its participants the teacher and his students. Creating favorable and friendly atmosphere at the lessons has a positive character. Respecting students, lacking assessment of the personality, causes desire to attend classes, liberates that is important at learning of foreign language. Thus the language barriers are removed, and it is easier to students to switch to its perception.

"It is very important to the student considering the teacher as his mentor, to ask him for the help during educational process, to discuss the issues concerning him (even if they are remotely connected with a topic of the lesson). The teacher has to use an effective form of motivation is to strengthen confidence in own forces of the student. The more trust the students, the more willingly they cooperate with the teacher in the process of training" [3]. The teacher should believe in success of the students that can find reflection in organizing an after-hour events in a foreign language or holding examination in a non-standard form. The non-standard form of holding examination means a high level of self-organization and responsibility of the students, their readiness for independent work and receiving assessment for it. Besides, during such work there is not only a demonstration of the gained knowledge, but also implementing creative abilities and potential of the students that has a positive impact.

\section{CONCLUSION}

Creating a favorable motivating atmosphere is the important aspect of training demanding a careful thoughtover approach, desire and interest of the teacher in getting the result connected with development of the discipline. The foreign language is a many-sided and variable discipline; it is one of the main "instruments for education of the students having all-planetary thinking" [7]. Using new techniques of training and implementing new technologies of education will help at achievement of a goal which result is the ability of students to perceive and reproduce the learned foreign language taking into account professional education.

\section{REFERENCES}

[1] I.K. Lapshina. Polylevel of culture of the modern world and problem of arts education, The problems of modern linguistic education: reports and theses of reports on international scientific conference on March 27-29, 2003 devoted to the 40 anniversary of faculty of foreign languages. In 2volumes, vol. 1, Vladimir: VGPU, 2003, pp. 201-210.

[2] Yu. V. Bogdanov. Motivating student to training: theory and practice, Terra Economicus, vol. 11, no 4-3, 2013, p. 254.

[3] N.V. Mormuzheva. Motivation training of students at professional educational institutions. // Pedagogy: traditions and innovations: materials of IV International Scientific Conference (Chelyabinsk, December, 2013), Chelyabinsk: Two Komsomol members, 2013, pp. $160-163$.

[4] S.G. Ter-Minasova. Language and cross-cultural communication, Moscow: Slovo/Slovo, 2000, 144 p

[5] O.M. Ryabtseva. Ways of increasing motivation in learning foreign language, News of Southern Federal University. Technical sciences. Part II. The problems of pedagogy and methodic of teaching foreign languages, 2012, pp. 125-129.

[6] A.S. Podol'ko. Modeling cross-cultural communication on the example of a lesson of a foreign language, Bulletin of Chelyabinsk State University, no.43 (181). Philology. Art criticism. Issue 39, 2009, pp. 116-119.

[7] P.V. Sysoev. Training in cultural self-determination and dialogue of cultures by means of a foreign language, http://www. prof. msu.ru/publ/omsk2/o35.htm. 